\title{
Asymmetric behavior of Australia's big-4 banks in the mortgage market
}

This paper presents an alternative framework for modeling the behavior of banks in setting lending and/or saving rates. In a short-run dynamic model, we correct for deviations from the long-run path using three feedback coefficients capturing different disequilibria. This enables us to test for both amount and adjustment asymmetries by considering the size and direction of any deviations. We use this model to examine the relationship between the official cash rate (set by the Reserve Bank of Australia as a monetary policy tool) and the standard variable mortgage rates of Australian Big-4 banks using weekly data from 2001 to 2012. The evidence indicates both types of asymmetries along with synchronized rate-setting behavior. Overall, the banks immediately pass on 120 percent of any rate rise, but only 85 percent of any rate cut. Further, when mortgage rates are substantially above the equilibrium path, we find no significant attempt to lower rates, but faster adjustment when rates are below equilibrium values. This finding has important implications for the RBA's monetary policy transmission mechanism and the effectiveness of the expansionary versus contractionary policy.

Keywords: monetary policy; mortgages interest rates; asymmetric behavior, Australia JEL Classification: C22; E58; G21

\section{Introduction}

In the US, 15 and 30-year-fixed-rate mortgages dominate the residential home loan market, accounting for more than 93 percent of mortgages originated since 2009 and 82 percent of the total stock of outstanding loans (Fuster and Vickery, 2013). Outside the US,

\footnotetext{
* We wish to thank Professor Stephen Hall and an anonymous referee, whose useful suggestions considerably improved an earlier version of this article. The usual caveat applies.
} 
however, including in the UK and the rest of the European Union, Canada, and Australia, variable (or adjustable) rate mortgages universally prevail, with fixed rate instruments seldom available for terms of more than 3-5 years. The Australian residential mortgage market is one of the country's most important retail financial markets, not least from the perspective of households and lenders, but also from that of Australia's central bank, the Reserve Bank of Australia (RBA).

From the household point of view, as at March 2012, some 67 percent of Australian households possessed residential property (either owned outright or mortgaged), with 36 percent of households bearing a home loan, with a median value of \$200 thousand for debtholding households and gearing (the ratio of home loan debt to assets) of 44 percent (RBA, 2012a). Consequently, Australian households are now among the most indebted in the world by some accounts, with globally and historically high levels of debt gearing and service (interest payments on debt to income) and increasingly unaffordable housing markets (Worthington, 2012). From the lender perspective, more than one hundred lenders offering literally thousands of products have ever-increasingly competed for a share of the \$1.2 trillion mortgage market with net interest margins (the difference between lending rates and funding costs) becoming progressively narrower and financially savvy households increasing attuned to the different attributes of the many competing products offered. Such market competition has been constantly on the rise since the 1990s following the deregulation of the financial system and globalisation of financial markets (Esho, Kofman and Sharpe, 2005). Finally, as residential mortgages are an important part of the monetary policy transmission mechanism in Australia, moves by the RBA in setting short-term interest rates continue to exert a powerful impact on household disposable income.

Smales (2012) examined the Australian interest rate futures market reaction to changes in the cash rate and found compelling evidence of asymmetric volatility responses to bad rather 
than good news. In general, changes in the cash rate can affect the spectrum of interest rates from the money to the capital markets, particularly with a stronger reaction evident in short term interest rates. There is, of course, a link here in that while many factors affect mortgage rates — including the cost of funding, credit and liquidity risk, and marketing strategies_efforts made by the RBA in the pursuit of monetary policy are a primary determinant of the level of funding costs and hence the level of lending rates (Deans and Stewart, 2012). Since 1990, the RBA has targeted the desired interest rate on overnight loans in the money market. This policy instrument, referred to as the cash rate, is the equivalent of the federal funds rate in the US. While other influences on funding costs, including market risk premia and competitive pressures, are unaffected by the cash rate, analyzing the asymmetric behavior of banks in response to changes in the cash rate is still considered one of the more topical issues with tangible implications for borrowers. In particular, the extent of the asymmetric pass-through of funding cost into mortgage interest rates is important because it influences competition in the banking sector with significant consequences for social welfare (Kobayashi, 2008). For example, relative mortgage rates affect decisions by consumers on switching loans from one lender to another, while the speed and accuracy with which rate cuts and increases are passed on to borrowers, especially among highly indebted households, impacts significantly upon their financial wellbeing.

In response, a growing number of studies have investigated differences in the pass-through of monetary policy interest rate changes into mortgage rates in a range of market contexts. We can generally classify these previous studies into two main groups. The first of these identify asymmetry in short-run changes in mortgage rates that favor lenders. See, for instance, Hannan and Berger (1991), Lowe and Rohling (1992), Lowe (1995), Mojon (2000), Hofmann and Mizen (2004), Payne (2007a, 2007b), Toolsema and Jacobs (2007), Payne and Waters (2008), Kim and Nguyen (2008), de Haan and Sterken (2011), and Valadkhani and Anwar (2012). For 
example, Hofmann and Mizen (2004) examined the interplay between 90-day deposit and mortgage rates for seven banks and found evidence of downward rigidity in the UK, US, and Dutch mortgage markets. Likewise, Payne and Waters (2008) analyzed the long-term interest rate pass-through of the federal funds rate to the prime rate over the period February 1987October 2005, also concluded that the response of the prime rate to changes in the federal funds rate was asymmetric.

The second group of these studies argues that this asymmetric behavior largely favors borrowers. See, among others, Frost and Bowden (1999) and Liu, Margaritis and Tourani-Rad (2008) for the analysis of mortgage interest rates in New Zealand, Chong, Liu and Shrestha (2006) in Singapore, and Lim (2001) in Australia. For example, Liu, Margaritis and TouraniRad (2008) found that in contrast to the evidence concerning short-run pass-through, the longrun pass-through for most retail rates in New Zealand was complete. Similarly, using aggregate data over the period 1990-2000, Lim (2001) modeled the asymmetric adjustments between three Australian bank interest rates, employing a multivariate asymmetric error-correction model to examine the long- and short-run interplay between the levels of rates and the shortrun relationships between rate changes. Lim’s (2001, p. 146) findings suggest “...banks value their borrowing customers and tend to pass on decreases in the loan rates faster than they pass on increases".

Elsewhere with Australian data, Lowe and Rohling (1992) examined the asymmetric effects of changes in the funding cost on the mortgage rate. However, their study only tested for the amount asymmetry but not the adjustment asymmetry and the sample is now clearly outdated. Lowe and Rohling (1992) provided two explanations for the stickiness of various types of Australian loan rates, including the mortgage rate: switching costs (such as loan establishment fees, stamp duty, and early repayment fees), and risk sharing. Lowe and Rohling (1992, p. 11) also stated that “...if borrowers are more risk averse than the shareholders of the 
bank, there exists an implicit risk insurance argument for the stickiness of interest rates”. They further assert that changes in the cash rate can have little influence on mortgage rates when competition is weak and customers' decisions are interest rate inelastic.

More recently, Lim, Tsiaplias and Chua (2013) developed an innovative framework to examine the time-varying interactions between bank and official interest rates for banking systems in the US and Australia. Their small-scale model determines three interest rates (i.e. deposit, loan, and money market rates) simultaneously for both countries over a period characterized by a number of structural changes in market and credit conditions and different monetary policy stances. In that analysis, the pass-through parameters and the intermediation markups change in response to the emergence of the global financial crisis. In other words, their proposed approach generated time-varying bank interest rate adjustments. The key findings were that unlike the US, pass-through was relatively higher on Australian loan rates. Further, prior to the most-recent financial crisis, the RBA set the cash rate quite independently of banking behavior, but in the post-GFC era the relationship between bank and official interest rates became somewhat interactive.

In this paper, using weekly mortgage rate data from 22 January 2001 to 5 March 2012, we examine the short- and long-run relationships between the official cash rate set by the RBA and the standard variable mortgage rates of Australia's Big-4 banks. These banks—comprising the ANZ Bank (ANZ), Commonwealth Bank of Australia (CBA), National Australia Bank (NAB), and Westpac Banking Corporation (WBC)—collectively account for nearly 85 percent of the residential mortgage market.

Compared with the extant literature, the main contributions of this paper are as follows. First, we propose an alternative approach in modeling any asymmetry in adjustment, whereby we take into account both the magnitude and the sign of the disequilibria. Second, a dynamic least squares method is employed to accommodate the possibility of endogeneity between 
monetary policy decisions by the Australian central bank and the responses by the Big-4 banks. Finally, we move beyond the prevailing use of aggregate data to the lender level. This allows us to gain greater insight into the extent and speed with which major banks repress potential rate cuts and pass on rate increases, and therefore resulting in an in-depth understanding of competition in this important retail financial market.

The remainder of the paper is organized as follows. Section 2 concisely presents the theoretical framework used for testing both the amount and adjustment asymmetries. Section 3 discusses the sources and description of the data employed. After examining the time series properties of the data, Section 4 presents the estimated long- and short-run dynamic models for each of the Big-4 banks followed by the test results for the amount and adjustment asymmetries as well as causality. Section 5 highlights the policy implications of the study and discusses briefly some directions for future research. Finally, Section 6 concludes the paper.

\section{Theoretical framework}

Following Rousseas (1985), Scholnick (1996), Toolsema and Jacobs (2007) and de Haan and Sterken (2011), we assume that in the long run the Big-4 banks set their standard variable mortgage rates as a markup on the cash rate. However, there is the possibility of endogeneity between the cash rate and individual bank mortgage rates. In evidence, Lim, Tsiaplias and Chua (2013, p. 1) argue that any empirical analysis of adjustments in bank interest rates should allow for feedbacks from bank rates to policy interest rates given the emergence of several episodes of credit crises. Due to the possibility of endogeneity between the two interest rate series, we use the dynamic least squares (DLS) method (Stock and Watson, 1993) to estimate the long-run relationship between the RBA's cash rate and the standard variable mortgage rates. In order to eliminate the serial correlation and asymptotic endogeneity between $R_{i t}$ and 
$C_{t}$ in equation (1), in this method up to $k$ lags and leads of changes in the cash rate, i.e. $\sum_{j=-k}^{i=+k} b_{i j} \Delta C_{t-j}$ are included in equation (1). That is:

$R_{i t}=\theta_{0 i}+\theta_{1 i} T_{t}+\theta_{2 i} C_{t}+\sum_{j=-k}^{i=+k} b_{i j} \Delta C_{t-j}+\varepsilon_{i t}$

where $R_{i t}$ is the standard variable mortgage rate of the $i^{\text {th }}$ bank at period $t$ where $i=1$ for ANZ, 2 for $\mathrm{CBA}, 3$ for $\mathrm{NAB}$, and 4 for $\mathrm{WBC}, C_{t}$ is the cash rate at time $t, \theta_{1 i}$ is the estimated coefficient for a trend variable $\left(T_{t}\right), \theta_{0 i}$ and $\theta_{2 i}$ are respectively the average long-run markup and pass-through coefficients for the $i^{\text {th }}$ bank, and $\varepsilon_{i t}$ is the residual term.

All other things being equal, as banks are all assumed to be profit maximizers, when the RBA increases the cash rate as part of its tightening monetary policy stance, the standard variable mortgage rate is also expected to rise, hence $\theta_{2 i}$ is positive. If $\theta_{2 i}$ is equal to unity, the long-run pass-through is said to be complete. According to Rousseas (1985) and Valadkhani (2014), with a positive $\theta_{0 i}$ mark-up coefficient banks can still make profits while the passthrough coefficient $\theta_{2 i}$ is near unity. Failure to pass the RBA's rate changes onto borrowers will undermine the efficacy of monetary policy. Similar long-term relationships between the benchmark and various retail lending rates have been widely utilized in the literature, see inter alia Heffernan (1997), Chong, Liu and Shrestha (2006), and Liu, Margaritis and Tourani-Rad (2008).

Most previous studies (Sarno and Thornton, 2003; Chong, Liu and Shrestha, 2006; Payne, 2007a, 2007b; Liu, Margaritis and Tourani-Rad, 2008; Chong, 2010) consider two types of deviations from the long-run equilibrium path, namely positive and negative. However, the responses of banks to small/large and positive/negative deviations can vary significantly. We 
can empirically verify this by incorporating three error correction terms into the following short-run dynamic model:

$\Phi_{k}(L) \Delta R_{i t}=a_{0 i}+\sum_{j=0}^{q} \lambda_{i j}^{+} \Delta C_{t-j}^{+}+\sum_{j=0}^{q} \lambda_{i j}^{-} \Delta C_{t-j}^{-}+\omega_{L i}^{+} \varepsilon_{L i t-1}^{+}+\omega_{L i}^{-} \varepsilon_{L i t-1}^{-}+\omega_{S i}^{ \pm} \varepsilon_{S i t-1}^{ \pm}+v_{i t}$

where $\Phi_{k}(L)=\left(1-\rho_{1} L-\rho_{2} L^{2}-\ldots-\rho_{k} L^{k}\right)=$ a $k$-order polynomial lag operator (which is assumed to have no zero within or on the unit circle), $k=$ the number of autoregressive terms; $a_{0 i}=$ the corresponding intercept term; $\lambda_{i j}^{+}$and $\lambda_{i j}^{-}$are the short-run effects of positive and negative changes in the cash rate on the standard variable mortgage rate of the $i^{\text {th }}$ bank at time $t-j$. We use superscripts + and - to indicate the positive and negative changes of the series, respectively. That is:

$\Delta C_{t}^{+}=\max \left\{\Delta C_{t}^{+}, 0\right\} \Rightarrow \Delta C_{t}^{+}=\Delta C_{t}$ if $\Delta C_{t}>0$ and $\Delta C_{t}^{+}=0$ if $\Delta C_{t} \leq 0$

$\Delta C_{t}^{-}=\min \left\{\Delta C_{t}^{-}, 0\right\} \Rightarrow \Delta C_{t}^{-}=\Delta C_{t}$ if $\Delta C_{t} \leq 0$ and $\Delta C_{t}^{-}=0$ if $\Delta C_{t}>0$

The estimated residual term obtained from equation (1) i.e. $\hat{\varepsilon}_{i t}$, is widely used as a proxy for measuring the magnitude of the disequilibrium. We split this term into three sub-series of almost the same length by using z score in a normal distribution as follows:

$\hat{\varepsilon}_{\text {Lit }}^{+}=\hat{\varepsilon}_{i t}$ if $\hat{\varepsilon}_{i t} \geq 0.44 \hat{\sigma}_{i}, \hat{\varepsilon}_{i t}^{+}=0$ otherwise

$\hat{\varepsilon}_{L i t}^{-}=\hat{\varepsilon}_{i t}$ if $\hat{\varepsilon}_{i t} \leq-0.44 \hat{\sigma}_{i}, \hat{\varepsilon}_{i t}^{-}=0$ otherwise

$\hat{\varepsilon}_{\text {Sit }}^{ \pm}=\hat{\varepsilon}_{i t}$ if $-0.44 \hat{\sigma}_{i}<\hat{\varepsilon}_{i t}<0.44 \hat{\sigma}_{i}, \hat{\varepsilon}_{i t}^{ \pm}=0$ otherwise

Where $\hat{\sigma}_{i}$ is the estimated standard deviation of $\hat{\varepsilon}_{i t}$, whereby $\hat{\varepsilon}_{i t} \square \operatorname{NID}\left(0, \hat{\sigma}_{i}\right)$. Figure 1 depicts how each $\hat{\varepsilon}_{t}$ is divided into three subseries using a normal distribution. The areas indicated by $\hat{\varepsilon}_{t} \geq 0.44 \hat{\sigma}$ and $\hat{\varepsilon}_{t} \leq-0.44 \hat{\sigma}$ respectively, represent "large positive" and "large negative" parts of the series, each accounting for approximately one-third of the distribution. The middle area 
at the bottom of the graph covers the remaining 34\% small-medium negative/positive values around the mean of zero. Note that the area under the normal curve (or a $\mathrm{Z}$ table) from 0 to \pm 0.44 is approximately 0.33 .

\section{[FIGURE 1 ABOUT HERE]}

As shown in equation (2), there are three different feedback coefficients (representing the varying speeds of adjustment) when the deviations from the long-run path are assumed to be relatively: positive and large $\left(\omega_{L i}^{+}\right)$, negative and large $\left(\omega_{L i}^{-}\right)$, and small positive or small negative $\left(\omega_{S i}^{ \pm}\right)$. We expect that $\omega_{L i}^{+}, \omega_{L i}^{-}$and $\omega_{S i}^{ \pm}<0$. Because we use high frequency data (i.e. weekly), we model any possible autoregressive conditional heteroscedasticity (ARCH) and generalized ARCH (GARCH) effects in the residual series $\left(v_{i t}\right)$ of equation (2) using a GARCH(1,1) framework and the maximum likelihood estimation method.

Once we have estimated equation (2), we can test the applicability of both the amount of asymmetry $\sum_{j=0}^{q} \lambda_{i j}^{+}=\sum_{j=0}^{q} \lambda_{i j}^{-}$and the adjustment asymmetry $\omega_{L i}^{+}=\omega_{L i}^{-}=\omega_{S i}^{ \pm}$using a Wald test. First, if we reject the null hypothesis $\sum_{j=0}^{q} \lambda_{i j}^{+}=\sum_{j=0}^{q} \lambda_{i j}^{-}$vs. $\sum_{j=0}^{q} \lambda_{i j}^{+}>\sum_{j=0}^{q} \lambda_{i j}^{-}$, then we argue that in the short run banks pass on the official rate rises to borrowers more than they do for rate cuts. The literature refers to this phenomenon as the amount asymmetry. Second, if we reject the null hypotheses $\omega_{L j}^{+}=\omega_{L j}^{-}$or $\omega_{L i}^{+}=\omega_{L i}^{-}=\omega_{S i}^{ \pm}$(while $\left|\omega_{L i}^{-}\right|>\left|\omega_{L i}^{+}\right|$), we conclude that the speed of adjustment towards the long-run path is also asymmetric.

Thus, a lagged large negative disequilibrium between the actual mortgage rate and its equilibrium path leads to a faster error correction mechanism relative to a large positive disequilibrium. This means that whenever actual mortgage rates in the short run are substantially lower than the long-run path $\left(\hat{\varepsilon}_{i t} \leq-0.44 \hat{\sigma}_{i}\right)$, banks raise their lending rates as fast 
as they can to restore the long-run market equilibrium. Conversely, when $\omega_{L i}^{+}$is not statistically significant and, at the same time, actual mortgage rates are substantially higher than the equilibrium value $\left(\hat{\varepsilon}_{i t} \geq 0.44 \hat{\sigma}_{i}\right)$, banks hesitate to lower lending rates, hence resulting in a nonexistent, or at best, a very sluggish, speed of adjustment. We use disaggregated data in which the extent of adjustment asymmetry is examined by testing both the size and direction of changes in the error correction terms. For a detailed account of the amount and adjustment asymmetries, see Valadkhani and Anwar (2012), de Haan and Sterken (2011) and Allen and McVanel (2009).

It is also useful to examine whether there is any evidence of coordinated rate setting by the Big 4 banks and use this to identify which banks are "leaders" and which are "followers" in terms of rate changes during the sample period. This knowledge would significantly enhance our understanding of interest-rate setting behavior in the retail mortgage market. For this purpose, we employ a pairwise Granger causality test by adopting the following four-variable vector autoregression (VAR) model to capture the short-run dynamic interactions between changes in the standard variable mortgage rates of the Big-4 banks:

$$
\Delta \hat{R}_{i t}=\hat{\xi}_{i 0}+\sum_{j=1}^{k=4} \hat{\phi}_{i j} \Delta \hat{R}_{1 t-j}+\sum_{j=1}^{k=4} \hat{\varphi}_{i j} \Delta \hat{R}_{2 t-j}+\sum_{j=1}^{k=4} \hat{\mu}_{i j} \Delta \hat{R}_{3 t-j}+\sum_{j=1}^{k=4} \hat{\eta}_{i j} \Delta \hat{R}_{4 t-j}
$$

\section{Data}

We obtain official cash rate data from the RBA (2012b) and convert the daily observations to a weekly frequency so that they are comparable with the data frequency available for the standard variable mortgage rates. The standard variable mortgage rates for the Big-4 banks are obtained from www.canstar.com.au for which only weekly data are available. In this regard, Brännäs and Ohlsson (1999) suggest that the detection of asymmetry behavior in a series is mainly dependent upon the frequency of the series concerned, proving that the use of 
aggregated frequencies (such as annual, quarterly and monthly observations) may mask any existing asymmetries. Therefore, we use weekly data to detect any discernable asymmetric behavior not easily observable when using the aggregate data.

Figure 2 plots the cash rate and the variable mortgage rates of the Big-4 banks over the period January 2001 to March 2012. While both the cash rate and mortgage rates are clearly variable, but with persistent periods of decreasing and increasing rates, it would appear at first impression that the mortgage rates are tracking the cash rate throughout most of this period. We can also observe some evidence of asymmetric rate setting behavior by Australia's Big-4 banks. For example, as shown in Figure 2, when the cash rate was generally increasing in the period 2002-2009, the Big-4 banks increased their mortgage rates by about the same magnitude (if not more) and so the mortgage rate-cash rate spread was more or less constant. However, when the RBA started reducing the cash rate after 2009, the decline in the Big-4 mortgage rates was not of the same magnitude. This suggests that the Big-4 banks either delayed cutting mortgage rates as the cash rate fell or did not pass on the full rate cut.

\section{[FIGURE 2 ABOUT HERE]}

Table 1 provides descriptive statistics of the data for three separate periods, the period from January 2001 to December 2007, the period from January 2008 to 5 March 2012, and finally the entire sample period comprising of 581 weekly observations. As shown in Table 1, while the average cash rate fell from 5.33 percent in the first period to 4.72 percent in the post2008 period, the average standard variable mortgage rate for all four banks rose. The standard deviations in Table 1 also suggest that all series were generally more volatile during the second period. During the entire sample period, all four mortgage rate series are positively skewed with excess kurtosis, thus the Jarque Bera test of normality is rejected for each series. However, for the cash rate the normality assumption cannot be rejected at the 5 or even 10 percent level of significance. 


\section{[TABLE 1 ABOUT HERE]}

Based on the information in Figure 2 and Table 1, it would appear that during the sample period WBC and NAB had relatively the highest and lowest mortgage rates, respectively. Similarly, we also observed that the spread between the cash rate and the mortgage rate was widest for WBC and smallest for NAB. This observation holds for most of this sample period. Therefore, one can conclude that of the Big-4 banks, NAB and WBC could be respectively described as the "friendliest" and the "least friendly" lenders, at least insofar as the average mortgage rate-cash rate spread is concerned.

The question remains as to what circumstances explain the widening spread in the cash rate and mortgage rates. Based on a comprehensive cross-country study of bank interest margins in Germany, France, the UK, Italy and Spain during the period 1993-2000, Maudos and Fernandez de Guevara (2004, p. 2277) argue that in general “the 'pure' interest margin depends on the competitive conditions of the market, the interest rate risk, the credit risk, the average operating expenses and the risk aversion of banking firms, as well as ... opportunity cost of reserves, payment of implicit interest and quality of management.”

In Australia, Deans and Stewart (2012) argue that three major changes have taken place in the composition of the funding of the major banks since the GFC. First, the major banks have moved away from short-term wholesale funding towards long-term wholesale funding. Second, at the same time, the major banks have increased their use of deposits and decreased their use of short-term debt. Finally, within bank deposit funding, the banks have shifted towards term deposits and away from others types of deposit, with term deposits in fact providing much of the growth in deposit funding during the post-GFC period (Deans and Stewart 2012). Putting aside these longer-term changes, the important issue here is that according to Figure 2 the gap between the mortgage rate and the cash rate typically widens only when the cash rate is falling.

One cannot observe such behaviour at times when the cash rate was on the rise. In the 
following section, we formally test the extent and nature of this asymmetric behavior among the Big-4 banks.

\section{Empirical results}

Prior to undertaking any further empirical analysis, it is important to examine the time series properties of the data. For this purpose, Table 2 shows the results of three conventional unit root tests, namely, the augmented Dickey-Fuller (Dickey and Fuller, 1981) test, the Kwiatkowski-Phillips-Schmidt-Shin (KPSS, 1992) test and the Phillips-Perron (PP, 1988) test, along with the Enders and Granger’s (EG, 1998) momentum threshold autoregressive (MTAR) test with asymmetric adjustment. We used the lowest value of the Schwarz information criterion to determine the optimal lag length in the test regressions. All four tests consistently suggest that the cash rate and the Big-4 banks' standard variable mortgage rates are integrated of order one or I(1).

Based on the results of the unit root tests (ADF, KPSS, PP, and MTAR) reported in Table 3, the residuals of the estimated equation (1) for each bank become stationary only when both the constant and a trend variable are included in the long-run cointegrating vectors. Therefore, the resulting residuals of equation (1) in which the constant and a trend variable are highly significant can be used as an error correction mechanism in the next stage to specify an asymmetric short-run dynamic model. Lowe (1995) and Valadkhani and Anwar (2012) also concluded that the RBA cash rate and the aggregated standard variable mortgage rate are cointegrated.

\section{[TABLES 2 AND 3 ABOUT HERE]}

After establishing that all of the variables in equation (1) are I(1), we then adopt the DLS method to estimate the possible long-run relationship between the cash rate and the 
corresponding standard variable mortgage rate for each bank. Table 3 presents the estimates for each of the four banks with and without trend. In terms of goodness-of-fit statistics, all of the four estimated models (with both constant and trend) perform much better than those with an intercept only. We can also see that values of the observed $\bar{R}^{2}$ vary little from a minimum of 0.961 for WBC (both constant and trend) to a maximum of 0.976 for NAB. All of the estimated markup and pass-through parameters are statistically significant at the 1 percent level.

The question is which of the Big-4 banks has the highest long-run pass-through parameter, and at the same time, the lowest markup. In response, the results in Table 3 clearly suggest that irrespective of whether we include just constant or both a constant and trend in the estimated cointegrating vectors, NAB not only has the lowest long-run markup but also the highest passthrough parameter. The opposite holds for WBC. Allowing only a constant in the cointegrating vector, the markup varies from a minimum of 3.248 percent for NAB and a maximum of 3.528 percent for WBC. The corresponding pass-through parameters for NAB and WBC are 0.780 and 0.743 , respectively. Table 3 also shows that the null hypothesis of $H_{0}: \hat{\theta}_{2 j}=1$ is statistically rejected at the 1 percent level for all four banks. Based on the magnitudes of these markup and pass-through parameters, we thus conclude that in the long run NAB is the “friendliest lender" followed in order by CBA, ANZ and WBC. In work elsewhere, Lowe (1995) has attributed the incomplete pass-through parameter to the possibility that banks may smooth mortgage rates over the cycle in order to reduce the variability in the burden of borrower repayment.

\section{[TABLE 4 ABOUT HERE]}

We can now proceed to simultaneously estimate equation (2) and its residuals within a GARCH(1,1) model using a maximum likelihood method for each of the Big-4 banks. Table 4

presents the estimation results. Given the use of the first-difference form, $R^{2}$ varies from a 
minimum 0.379 (WBC) to a maximum of 0.477 (NAB), suggesting that the estimated short-run dynamic equations track the actual data very well. Both the ARCH and GARCH terms are statistically significant and the Bollerslev's non-negativity conditions are satisfied in each of the four estimated variance equations. The estimated GARCH coefficients suggest that volatilities in WBC (0.737) and CBA (0.701) are more persistent than those of ANZ (0.509) and NAB (0.509). The correlograms of standardized residuals squared were also examined (not shown but available upon request) and the insignificant values of the $Q$-statistics suggest that the GARCH(1,1) variance equations are adequate in capturing heteroskedasticity and volatility clustering in the residuals.

We adopted a general-to-specific methodology to exclude the statistically insignificant variables in equation (2) based on several maximum likelihood tests, except for the three error correction terms which are maintained for testing the adjustment asymmetries. Based on the estimated sum of the short-run coefficients of positive changes in the cash rate (i.e. $\lambda_{i 0}^{+}$and $\lambda_{i 1}^{+}$), if the RBA raises the cash rate by 1 percent, within 1 week the standard variable mortgage rates for ANZ, CBA, NAB and WBC will increase by 1.179, 1.227, 1.198 and 1.202 percent, respectively. However, when the RBA cuts its rate by 1 percent, within two weeks ANZ, CBA, NAB and WBC will lower their lending rate by only $0.899,0.864,0.870$ and 0.753 percent, respectively. The average responses of the Big-4 banks to a 1 percent rate rise (1.202 percent) and a 1 percent rate cut ( 0.846 percent) are comparable to the results of a recent study of the aggregate mortgage rate in Australia by Valadkhani and Anwar (2012) where in the short run the aggregate standard variable mortgage rate would increase by 1.16 percent and decrease by 0.84 percent in response to a 1 percent rise and fall in the cash rate, respectively.

We now briefly discuss the magnitude and statistical significance of the estimated individual coefficients for the three error-correction terms specified in equation (2). As shown in Table 4 , the estimated coefficient on $\hat{\varepsilon}_{\text {Lit-1 }}^{+}$(i.e. $\hat{\omega}_{L i}^{+}$) is not statistically significant for any of 
the four banks. This means whenever the actual mortgage rates are substantially above the equilibrium path, i.e. $\hat{\varepsilon}_{i t} \geq 0.44 \hat{\sigma}_{i}$, there will be no immediate adjustment in the short-run until another shock changes the market equilibrium. Under these circumstances, the Big-4 banks temporarily continue charging above the equilibrium rate.

Conversely, when actual lending rates are markedly below the market equilibrium (i.e. $\hat{\varepsilon}_{i t} \leq-0.44 \hat{\sigma}_{i}$ ), the Big-4 banks correct for the existing gap by lifting their rates with an average feedback coefficient of -0.148 per week, with NAB $\left(\hat{\omega}_{3 L}^{-}=-0.161\right)$ and ANZ ( $\hat{\omega}_{L}^{-}=-0.132$ ) being respectively the fastest and the slowest to respond. A cursory look at the magnitude and statistical significance of the four coefficients capturing relatively small positive/negative deviations from the long-run path, i.e. $\hat{\varepsilon}_{\text {Sit-1 }}^{ \pm}$, shows that unlike the other three banks, ANZ does not react significantly to small (positive or negative) deviations from the equilibrium path. As shown in Table 4 for each bank with no exception $\left|\hat{\omega}_{L}^{-}\right|>\left|\hat{\omega}_{S}^{ \pm}\right|>\left|\hat{\omega}_{L}^{+}\right|$. We can thus conclude that the asymmetric behavior demonstrated in these results clearly justifies splitting each error correction term into three series as specified in equation (2). Table 5 reveals that the sample size in the estimation procedure appears adequate as the number of non-zero weekly observations for each of these three series on average varies from 31 to 36 percent of total sample size. Thus, the estimated large positive deviations $\left(\hat{\varepsilon}_{L i t-1}^{+}\right)$, large negative deviations $\left(\hat{\varepsilon}_{\text {Lit-1 }}^{-}\right)$and small negative/positive deviations $\left(\hat{\varepsilon}_{\text {Sit-1 }}^{ \pm}\right)$across the Big-4 banks account for approximately one-third of the distribution.

\section{[TABLE 5 ABOUT HERE]}

Although the above discussion suggests the presence of both the amount and adjustment asymmetries, we formally now test the absence of such behavior. Table 4 presents the results of the short-run amount asymmetry and the long-run adjustment asymmetry using three Wald 
tests. The null hypothesis regarding the absence of the amount asymmetry i.e. $H_{0}^{1}: \sum_{j=0}^{1} \lambda_{i j}^{+}=\sum_{j=0}^{2} \lambda_{i j}^{-}$ is rejected at the 1 percent level of significance for all Big-4 banks. We can also test the absence of the adjustment asymmetry by using the following two null hypotheses: $H_{0}^{2}: \omega_{L i}^{+}=\omega_{L i}^{-}=\omega_{S i}^{ \pm}$and $H_{0}^{3}: \omega_{L i}^{+}=\omega_{L i}^{-}$. The lower part of Table 4 shows that both null hypotheses are again rejected at the 1 percent level of significance for all four banks and in all cases $\left|\hat{\omega}_{L i}^{-}\right|>\left|\hat{\omega}_{L i}^{+}\right|$and $\left|\hat{\omega}_{L i}^{-}\right|>\left|\hat{\omega}_{S i}^{ \pm}\right|$.

Therefore, when the actual lending rates are substantially below the market equilibrium, the speed of adjustment is greater than when (a) the rates are markedly above the equilibrium path, and (b) the deviations from the equilibrium path are relatively smaller. Valadkhani and Anwar (2012) have also provided convincing evidence of the applicability of both the amount and adjustment asymmetry in their recent aggregate study. Similar results were also obtained by previous studies (Heffernan, 1997; Payne, 2007a, 2007b; Toolsema and Jacobs, 2007).

A number of studies (Allen and McVanel, 2009; Liu, Margaritis and Tourani-Rad, 2011; de Haan and Sterken, 2011; Valakhani and Anwar, 2012) have previously captured both amount and adjustment asymmetries in short-run dynamic models for various lending interest rates. In terms of testing for adjustment asymmetry, these studies consider only the sign of the disequilibria by distinguishing only between positive and negative changes in the ECM terms, whereas the present study captures both the size and sign of the disequilibria. Comparing different deviations from the equilibrium values, our study thus examines if the detected asymmetric behaviour is size-dependent. In addition, Valadkhani and Anwar (2012) used monthly data (1989-2011) to examine the asymmetric behaviour of aggregate mortgage interest rate in response to dynamic changes in the RBA's cash rate. However, in this study we provide lender-specific results (including testing for asymmetry and causality) using weekly data for Big 4 banks which control $85 \%$ of the home loan market. Due to the use of aggregate and 
limited monthly observations, Valadkhani and Anwar (2012) (unlike the present study) could not estimate three size-dependent speeds of adjustment, when ECM deviations are relatively (1) positive and large, (2) negative and large, and (3) small positive or small negative.

In this paper we have decomposed the deviations from the long-run path into three separate components (large positive, large negative, and small positive/negative). This modeling approach then has useful policy implications as one can now conclude that the relevant regulatory bodies should closely monitor the asymmetric behavior of the Big-4 banks, particularly when there appears to be significant large negative disequilibria in the mortgage market.

In the remainder of this section, we examine if the Big-4 banks exhibit any coordinated behavior in setting their mortgage rates. Before presenting the Granger causality test results, it is useful to observe the average response times of the individual banks to changes in the cash rate during the sample period in Table 6. The magnitude and date for all of the RBA's rate cuts together with the first reactions of the Big-4 banks to such changes presented in the upper part of Table 6 in chronological order. For example, up until September 2008, it took exactly one week for each and every bank to respond (fully or partially) to the RBA's official rate cuts. In contrast, in the post-September 2008 period, it took on average 2.4 weeks for the Big- 4 banks to pass the rate cuts onto borrowers, ranging from a minimum average of 1.6 weeks for both CBA and WBC to a maximum of 3.3 in the case of ANZ. Based on these observations, it appears that since 2008 the Big-4 banks have been generally more hesitant to pass on rate cuts to borrowers, particularly ANZ and NAB.

\section{[TABLE 6 ABOUT HERE]}

Similarly, the magnitude and date of the RBA rate rises and the corresponding first responses of the individual banks (in weeks) are included in the bottom section of Table 6 . A cursory look at this part of Table 6 reveals a very interesting finding: since November 2003 the 
Big-4 banks have responded to the RBA rate rises within a week and, in just a few instances, two or four weeks. Since November 2003, the average response times of ANZ, CBA, NAB, and WBC to rate increases were 1.2, 1.0, 1.2 and 1.1 weeks, respectively, and the average of the Big-4 banks as a group was within 1.1 weeks. During the same period, the corresponding response time of the Big-4 banks to a rate cut was 2.3 weeks or nearly twice as slow. Therefore, we conclude that over time the Big-4 banks developed a tendency to pass rate cuts onto borrowers more slowly while at the same time accelerating the speed of passing on rate rises. These observations employ actual data and clearly confirm our previous econometric findings.

As discussed, in recent years whenever the RBA changes the cash rate, the response times of the Big-4 banks are systematically within one week (or on limited occasions, two or four weeks). This also provides further support as to why only the first two lags of changes in the cash rate are statistically significant in all of the estimated short-run dynamic models presented in Table 4. These observations motivated us to undertake a formal Granger causality test pairwise using the four-variable VAR model specified in equation (5). The Granger causality test results in Table 7 show that out of 12 possible null hypotheses, we reject 11 at the 1 percent level of significance. Based on these results, there is strong evidence of bi-directional causality between all pairs of Big-4 banks except for that from NAB to WBC. Therefore, according to Tables 6 and 7, there is irrefutable evidence of the coordination/synchronization of changes in the standard variable mortgage rates among the Big-4 banks. However coincidental, evidence of these synchronized and bi-directional responses among the Big-4 banks are somewhat worrisome, though further research is of course required.

[TABLE 7 ABOUT HERE] 


\section{Policy implications}

This paper addresses an important policy issue, which has not been hitherto investigated for major individual banks in Australia. In this paper we test for the two types of possible asymmetries (amount and adjustment). To the best of our knowledge, only three overseas studies and one Australian study have previously incorporated both amount and adjustment asymmetries in short-run dynamic models for mortgage rates. These four studies are as follows: (1) Allen and McVanel (2009) in their comprehensive analysis of the Canadian mortgage market; (2) de Haan and Sterken (2011) in their work on daily interest rate adjustment in the Dutch mortgage market; (3) Liu, Margaritis and Tourani-Rad (2011) in their thorough aggregate analysis of the interplay between the six-month deposit rate as a proxy for the funding cost and two retail interest rates (the standard variable mortgage rate and the business lending rate) in New Zealand; and (4) Valadkhani and Anwar (2012) in their recent examination of the asymmetric relationship between the cash rate and the aggregate standard variable mortgage rate.

The results of this paper can clearly assist mortgage holders and various regulatory bodies to identify systematically how the Big-4 banks' standard variable mortgage rates respond to changes in the cash rate. We found that in the short run the Big-4 banks passed on rate rises to borrowers faster than rate cuts and vice versa. In terms of rate cuts, there is not a great deal of difference among the four banks ( $\mathrm{ANZ}=1.179, \mathrm{CBA}=1.227, \mathrm{NAB}=1.198, \mathrm{WPC}=1.202$ ) as each bank raises its mortgage rate by approximately 1.20 percent in response to a 100 basis point increase in the official cash rate. However, when it comes to an equivalent rate cut, the account becomes more interesting as WBC's response ( 0.753 percent) differs markedly from the average response of the other Big-4 banks (0.878). One can thus argue that while there is econometric evidence of the amount asymmetry for all Big-4 banks, the extent of asymmetry for WBC is somewhat greater. 
As stated earlier, the Big-4 banks pass the RBA's rate cuts onto borrowers more slowly than rate rises. One explanation could relate to the fact that the effects on marginal borrowers are small, but the negative effects on bank profits are substantial if they do not raise lending rates quickly. Similarly, the positive effects are considerable if banks do not cut quickly. In evidence, it is believed that every day banks delay passing on a rate cut of 25 basis points adds \$6.2 million to their profits (Martin, 2012, p. 2). We similarly found evidence of the adjustment asymmetry, as the error correction term corresponding to the relatively larger positive deviations from the equilibrium path was not statistically significant and the same time, the opposite held for negatively larger deviations.

Overall, our results in terms of the magnitudes of both the amount and adjustment asymmetries (see Table 4) as well as the long-run estimated markup and pass-through parameters (see Table 3) suggest that during the sample period NAB could be described as the "friendliest lender". Given the fact that the Big-4 banks hold sway over 85 percent of the home loan market, our results can assist mortgage holders to borrow efficiently, and regulators to be more adequately equipped in protecting mortgage holders. The results of this paper suggest that there is a need for monitoring the behavior of the Big-4 banks particularly WBC, which exhibited a relatively higher markup, a lower pass-through, and at the same time greater amount asymmetry. Therefore, our results provide convincing evidence that the pass-through of monetary policy interest rate cuts into mortgage rates appear to be incomplete and, ceteris paribus, this makes the RBA’s expansionary monetary policy relatively less effective.

The results obtained in this paper can result in greater efficiency and transparency of the lending industry by offering an alternative analytical modeling framework for making a better assessment of the sources of asymmetric changes in mortgage rates. While we discuss our modeling framework in the context of the residential mortgage market, it can be easily adapted to examine the intricacies associated with the dynamic interplay between other types of retail 
and wholesale interest rates, including those for credit cards, personal loans, and business loans. Although the Big-4 banks dominate the retail mortgage market in Australia, other lenders (i.e. smaller regional banks, mortgage originators, building societies, and credit unions) can also be included in future studies. A similar approach as this study including other bank and non-bank lenders could enable us to obtain a more accurate picture of pricing behavior in the overall retail mortgage market. Such a comprehensive future study will also permit a more in-depth analysis of the roles of market share, funding mix, ownership, and the extent of securitization in mortgage rate pricing.

\section{Concluding remarks}

This paper presents a general testable framework that can be easily adapted to countries concerned with the asymmetric behavior of banks in setting lending and/or saving rates. Our proposed asymmetric short-run dynamic model can test more accurately for both the amount and adjustment asymmetries by splitting deviations from the long-run equilibrium path into three error correction subseries according to their sizes and signs. We use this model to examine the relationship between the official cash rate (set by the Reserve Bank of Australia) and the standard variable mortgage rates of the Big-4 banks using weekly data over the sample period 22 January 2001 to 5 March 2012. Given the varying responses to small/large (size) and negative/positive (sign) deviations from the long-run path, the use of the proposed model with three feedback coefficients is well justified.

We found that the standard variable mortgage rates of the Big-4 banks in Australia respond asymmetrically to changes in the cash rate in that they "shoot up like rockets" ("float down like feathers”) in response to a rate increase (decrease) by the RBA. Using 581 weekly observations over the sample period, we have substantiated by how much and how quickly each of the Big-4 banks will raise mortgage rates when the RBA increases the cash rate. We 
found that the banks mostly responded to the RBA's rate rises within one week, whereas their average response time to a rate cut was 2.3 weeks or more than twice as slow.

We conclude that during the sample period, the Big-4 banks developed the propensity to pass rate rises onto borrowers faster than rate cuts. Our results also indicate that NAB (WBC) has the lowest (highest) long-run markup and, at the same time, the highest (lowest) estimate of the pass-through parameter. Overall, if the RBA increases the cash rate by 1 percent, the standard variable mortgage rates for ANZ, CBA, NAB, and WBC instantaneously increase by 1.179, 1.227, 1.198, and 1.202 percent, respectively. However, when the RBA reduces its official cash rate by 1 percent, ANZ, CBA, NAB and WBC lower their standard variable mortgage rate by only $0.899,0.864,0.870$ and 0.753 percent, respectively.

In addition, when mortgage rates are substantially above the equilibrium path in the short run, none of the Big-4 banks makes any significant attempt to lower lending rates. However, when mortgage rates are markedly below equilibrium values temporarily, the banks eliminate the gap by increasing their lending rates at an average speed of -0.148 per week, with the NAB $(-0.161)$ and the ANZ $(-0.132)$ being the fastest and slowest to respond, respectively. Unlike the other three banks, we also found that ANZ reacts very sluggishly to small (positive or negative) deviations from the market equilibrium. Finally, bi-directional Granger causality test results among the Big-4 banks also provide significant evidence of the coordination/synchronization of changes in standard variable mortgage rates, which is an apparent cause for concern in terms of competition issues, but of course requires further attention.

Overall, the results of this paper can enhance the efficiency and transparency of the Australian mortgage market by capturing the varying responses of Australia's Big-4 banks to changes in the RBA's official cash rate. We conclude that a number of parties should more closely monitor the interest rate setting behavior of the Big-4 banks (particularly WBC). These 
include both retail mortgage holders and relevant regulatory bodies such as the Australian Competition and Consumer Commission (ACCC) in the interests of competition issues and consumer protection and the RBA itself in terms of better understanding the transmission mechanism of monetary policy. Asymmetric responses of Australia's Big-4 banks to the official cash rate have significant adverse effects on individual mortgage holders as well as wider implications for the effectiveness of monetary policy transmission in Australia. 


\section{References}

Allen, J., McVanel, D. 2009 Price movements in the Canadian residential mortgage market. Bank of Canada Working Paper 2009-13, Ottawa.

Brännäs, K., Ohlsson, H. 1999. Asymmetric time series and temporal aggregation, Review of Economics and Statistics 81, 341-44.

Chong, B.S. 2010. Interest rate deregulation: monetary policy efficacy and rate rigidity. Journal of Banking and Finance 30, 1467-484.

Chong, B.S., Liu, M.H., Shrestha, K. 2006. Monetary transmission via the administered interest rates channel. Journal of Banking and Finance 34, 1299-307.

Deans, C., Stewart, C. 2012. Banks' funding costs and lending rates. Reserve Bank of Australia’s Bulletin, March Quarter, Sydney.

de Haan, L., Sterken, E. 2011. Bank-specific daily interest rate adjustment in the Dutch mortgage market. Journal of Financial Services Research 39, 145-59.

Dickey, D., Fuller, W. 1981. Likelihood ratio tests for autoregressive time series with a unit root. Econometrica 49, 1057-1072.

Enders, W., Granger, C.W.J. 1998. Unit-root tests and asymmetric adjustment with an example using the term structure of interest rates. Journal of Business and Economic Statistics, 16(3), 304-11.

Esho, N., Kofman, P., Sharpe, I.G. 2005, Diversification, fee income, and credit union risk. Journal of Financial Services Research 27(3), 259-281.

Frost, D., Bowden, R. 1999. An asymmetry generator for error-correction mechanisms, with application to bank mortgage-rate dynamics. Journal of Business and Economic Statistics 17, 253-63.

Fuster, A., Vickery, J. 2013. Securitization and the fixed-rate mortgage. Federal Reserve Bank of New York Staff Reports no. 594.

Hannan, T.H., Berger, A.N. 1991. The rigidity of prices: evidence from the banking industry. American Economic Review 84, 938-45.

Heffernan, S.A. 1997. Modelling British interest rate adjustment: an error correction approach. Economica 65, 211-31.

Hofmann, B., Mizen, P. 2004. Interest rate pass-through and monetary transmission: evidence from individual financial institutions’ retail rates. Economica, 71, 99-123.

Karamujic, H.M. 2011. Comparative analysis of Australian residential mortgage (home loan) interest rates: evidence from two major Australian banks, Margin-The Journal of Applied Economic Research 5, 311-41.

Kim, S.J., Nguyen, D.Q.T. 2008. The reaction of the Australian financial markets to the interest rate news from the Reserve Bank of Australia and the U.S. Fed. Research in International Business and Finance 22(3), 378-95.

Kobayashi, T. 2008. Incomplete interest rate pass-through and optimal monetary policy. International Journal of Central Banking 4, 77-118.

Kwiatkowski, D., Phillips, P.C.B., Schmidt, P., Shin, Y. 1992. Testing the null hypothesis of stationarity against the alternative of a unit root: how sure are we that economic time series have a unit root? Journal of Econometrics 54, 159-78. 
Lim, G.C. 2001. Bank interest rate adjustments: are they asymmetric? Economic Record, 77(237) 135-47.

Lim, G.C., Tsiaplias, S., Chua, C.L. 2013. Bank and official interest rates: how do they interact over time? Economic Record 89(285), 160-174.

Liu, M.H., Margaritis, D., Tourani-Rad, A. 2008. Monetary policy transparency and passthrough of retail interest rates. Journal of Banking and Finance 32(4), 501-11.

Liu, M.H., Margaritis, D., Tourani-Rad, A. 2011. Asymmetric information and price competition in small business lending. Journal of Banking and Finance 35, 2189-196.

Liu, B., Skully, M., Tan, T. 2010. Effects of securitization on mortgage yield spreads in Australia. International Research Journal of Finance and Economics 50, 72-9.

Lowe, P. 1995. The link between the cash rate and market interest rates, Research Discussion Paper 9504. Economic Research Department, Reserve Bank of Australia.

Lowe, P., Rohling, T. 1992. Loan rate stickiness: theory and evidence. Research Discussion Paper 9206, Economic Research Department, Reserve Bank of Australia.

Martin, P. 2012. True to form, the big banks take with one hand-and with the other. The Age, October 4, p.2.

Maudos, J., Fernandez de Guevara, J. 2004. Factors explaining the interest margin in the banking sectors of the European Union. Journal of Banking and Finance 28, 2259-2281.

Mojon, B. 2000. Financial structure and the interest rate channel of ECB monetary policy. European Central Bank Working Paper No. 40, Frankfurt am Main.

Payne, J.E. 2007a. Interest rate pass through and asymmetries in adjustable rate mortgages. Applied Financial Economics 17(16-18), 1369-376.

Payne, J.E. 2007b. More on the monetary transmission mechanism: mortgage rates and the Federal funds rate. Journal of Post Keynesian Economics 29(2), 247-57.

Payne, J.E., Waters, G.A. 2008. Interest rate pass through and asymmetric adjustment: evidence from the Federal funds rate operating target period. Applied Economics 40(10-12), 1355362.

Phillips, P.C.B., Perron, P. 1988. Testing for a unit root in time series regression. Biometrika 75, 335-46.

Reserve Bank of Australia 2012a. Statistical Tables, Nonfinancial Sectors (Tables B21-24), Accessed 30 October, http://www.rba.gov.au/Statistics

Reserve Bank of Australia 2012b. Statistical Tables, Interest Rates (Tables F1 and F5), Accessed 15 September, http://www.rba.gov.au/Statistics

Rousseas, S. 1985. A mark up theory of bank loan rates. Journal of Post Keynesian Economics 8(1), 135-44.

Sarno, L., Thornton, D.L. 2003. The dynamic relationship between the Federal funds rate and the treasury bill rate: an empirical investigation. Journal of Banking and Finance 27, 1079110.

Scholnick, B. 1996. Asymmetric adjustment of commercial bank interest rates: evidence from Malaysia and Singapore. Journal of International Money and Finance 15, 485-96.

Smales, L. A. 2012. RBA monetary policy communication: The response of Australian interest rate futures to changes in RBA monetary policy. Pacific-Basin Finance Journal 20(5), 793808. 
Stock, J., Watson, M. 1993. A simple estimator of cointegrating vectors in higher order integrated systems. Econometrica 61(4), 783-820.

Toolsema, L.A., Jacobs, J.P.A.M. 2007. Why do prices rise faster than they fall? with an application to mortgage rates. Managerial and Decision Economics 28(7), 701-12.

Valadkhani, A. 2014. Analysing interest rate mark-ups in the Australian mortgage market. Journal of International Financial Markets, Institutions \& Money 31, 343-361.

Valadkhani, A., Anwar, S. 2012. Interest rate pass through and the asymmetric relationship between the cash rate and the mortgage rate. Economic Record 88(282), 341-50.

Worthington, A.C. 2012. The quarter century record on housing affordability, affordability drivers, and government policy responses in Australia. International Journal of Housing Markets and Analysis 5(3), 235-52. 


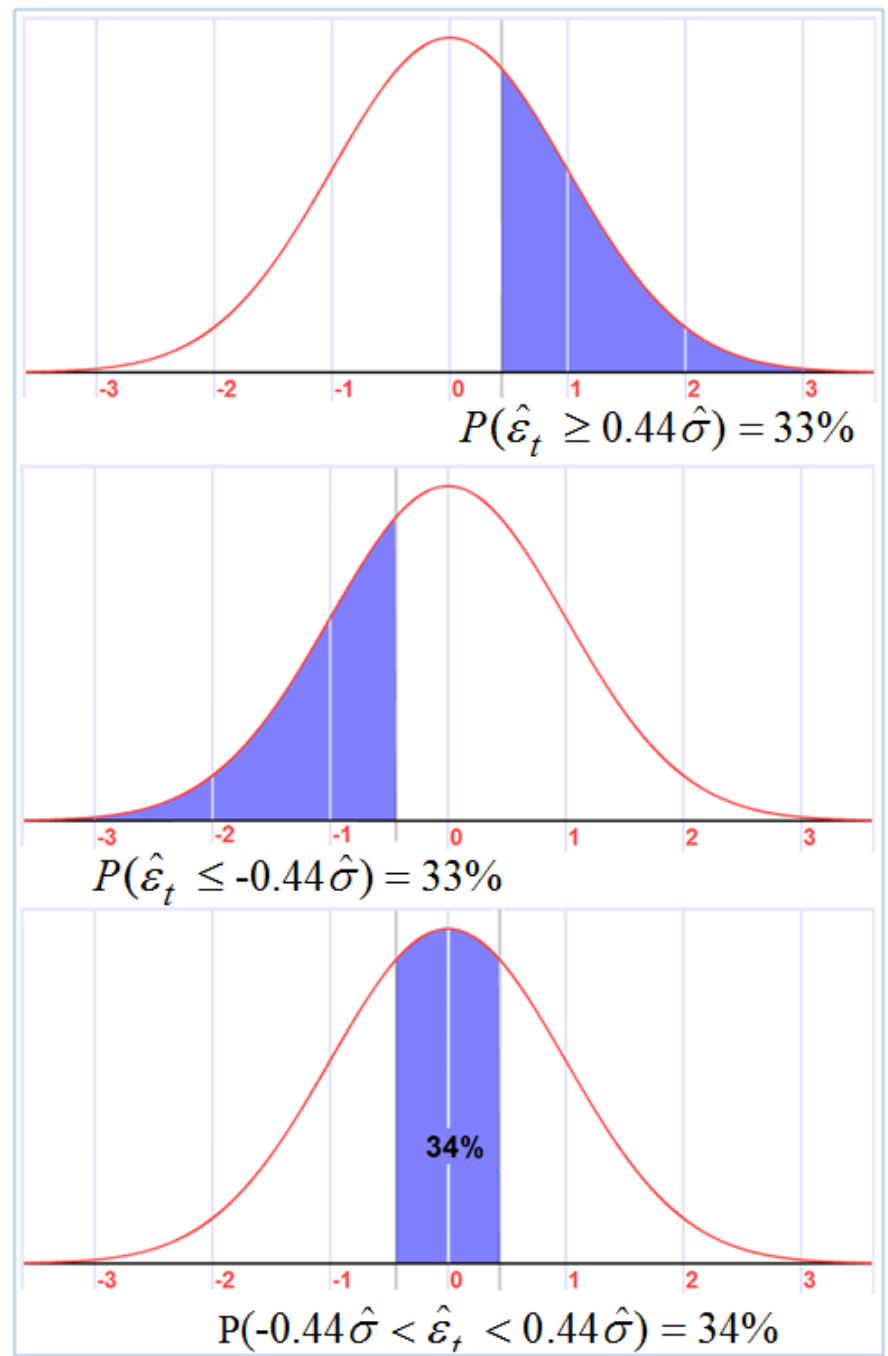

Fig. 1. Classification of $\hat{\varepsilon}_{i t}$ into three equal series.

Notes: In adopting a normal distribution, we assume that the three shaded areas above represent approximately one-third of the area under the normal curve: i.e. $\left(\hat{\varepsilon}_{i t} \geq 0.44 \hat{\sigma}_{i} ; \hat{\varepsilon}_{i t} \leq-0.44 \hat{\sigma}_{i} ;-0.44 \hat{\sigma}_{i}<\hat{\varepsilon}_{i t}<0.44 \hat{\sigma}_{i}\right) . \quad$ These three areas show relatively large positive, large negative and small-medium parts of the residual series. 


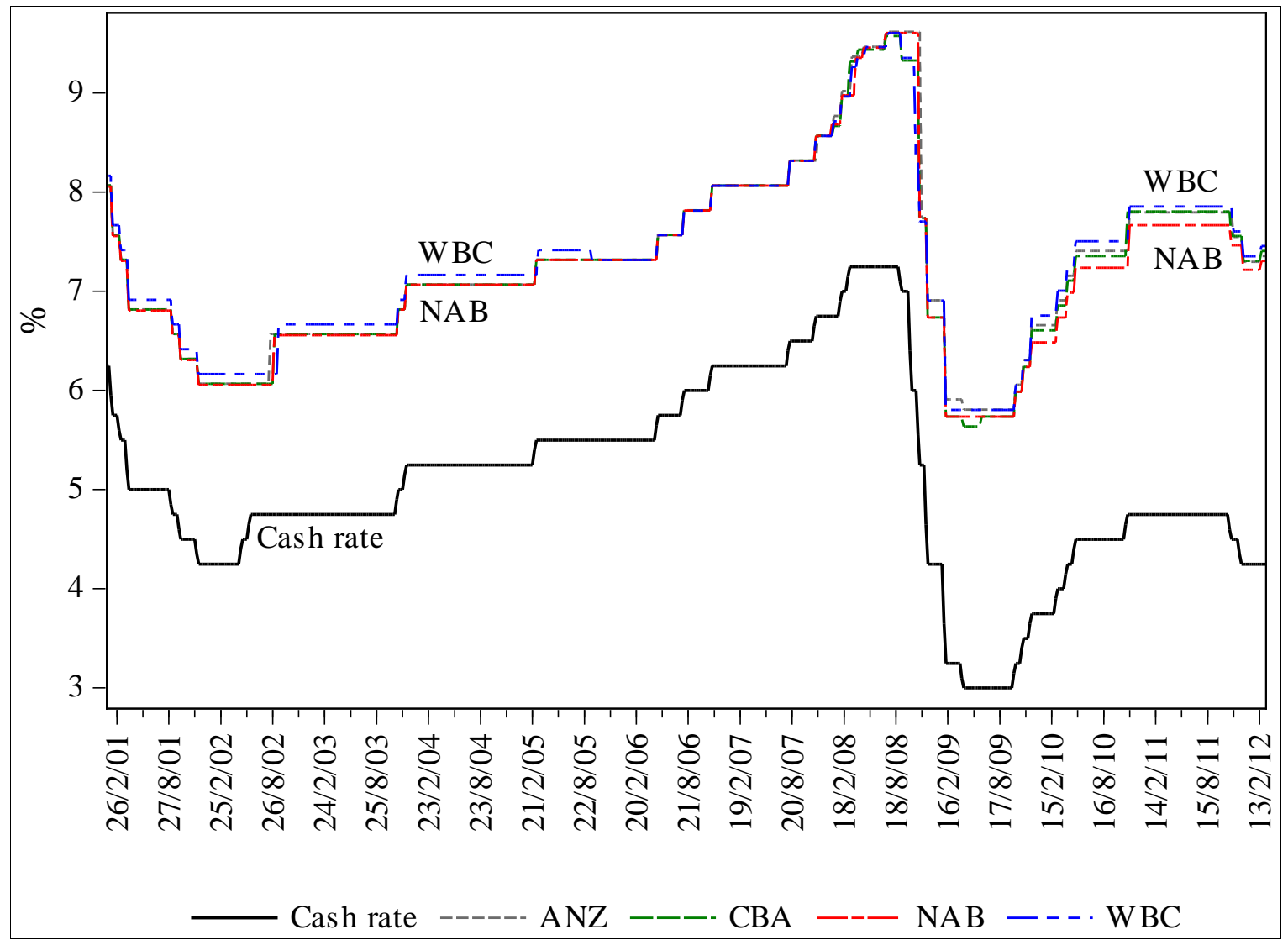

Fig. 2. Cash rate $\left(C_{t}\right)$ and the Big-4 banks' standard variable mortgage rates $\left(R_{i t}\right)$ Sources: RBA (2012b) and data purchased from canstar.com.au. 
Table 1

Descriptive statistics.

\begin{tabular}{lccccc}
\hline Banks & Mean $(\%)$ & $\begin{array}{l}\text { Std. } \\
\text { dev. } \\
(\%)\end{array}$ & Skewness & Kurtosis & $\begin{array}{c}\text { Jarque- } \\
\text { Bera }(\mathrm{JB})\end{array}$ \\
\hline \multicolumn{5}{c}{$22 / 01 / 200131 / 12 / 2007: 363$ weeks } \\
ANZ & 7.13 & 0.653 & 0.25 & 2.31 & $11.07^{* * *}$ \\
CBA & 7.13 & 0.657 & 0.25 & 2.31 & $10.87^{* * *}$ \\
NAB & 7.12 & 0.661 & 0.24 & 2.30 & $10.85^{* * *}$ \\
WBC & 7.19 & 0.626 & 0.20 & 2.36 & $8.58^{* * *}$ \\
Cash rate & 5.33 & 0.633 & 0.36 & 2.36 & $13.82^{* * *}$ \\
& $7 / 01 / 2008-5 / 03 / 2012: 218$ weeks & \\
ANZ & 7.53 & 1.165 & 0.30 & 2.33 & $7.25^{* *}$ \\
CBA & 7.47 & 1.170 & 0.18 & 2.29 & $5.81^{* *}$ \\
NAB & 7.42 & 1.182 & 0.40 & 2.39 & $9.02^{* * *}$ \\
WBC & 7.54 & 1.122 & 0.13 & 2.36 & 4.28 \\
Cash rate & 4.72 & 1.308 & 0.78 & 2.69 & $22.80^{* *}$ \\
ANZ & $22 / 01 / 20015 / 03 / 2012: 581$ weeks & \\
CBA & 7.28 & 0.901 & 0.67 & 3.41 & $47.03^{* * *}$ \\
NAB & 7.26 & 0.900 & 0.52 & 3.22 & $27.63^{* * *}$ \\
WBC & 7.23 & 0.903 & 0.66 & 3.46 & $47.36^{* * *}$ \\
\hline & 7.32 & 0.862 & 0.48 & 3.30 & $24.95^{* * *}$ \\
Cash rate & 5.10 & 0.989 & 0.14 & 3.01 & 1.81 \\
\hline
\end{tabular}

Notes: ${ }^{* *}$ and ${ }^{* * *}$ indicate that the null hypothesis is rejected at the 5 and 1 percent level of significance, respectively.

Sources: RBA (2012b), data purchased from canstar.com.au, and the authors' calculations. 
Table 2

Unit root tests.

\begin{tabular}{lcccc}
\hline Variable & ADF & KPSS & PP & EG \\
\hline $\begin{array}{l}\text { Constant and trend } \\
\text { Cash rate: } C_{t}\end{array}$ & -2.95 & $0.351^{* * *}$ & -1.87 & 0.87 \\
$\quad$ Variable mortgage rate: & & & & \\
$\quad$ ANZ: $R_{1 t}$ & -2.08 & $0.231^{* * *}$ & -2.38 & 2.25 \\
CBA: $R_{2 t}$ & -3.19 & $0.226^{* * *}$ & -2.41 & 2.22 \\
NAB: $R_{3 t}$ & -2.29 & $0.247^{* * *}$ & -2.41 & 2.17 \\
WBC: $R_{4 t}$ & -3.01 & $0.213^{* * *}$ & -2.41 & 2.46 \\
Constant only & & & & \\
$\Delta C_{t}$ & $-4.05^{* * *}$ & 0.096 & $-16.70^{* * *}$ & $39.87^{* * *}$ \\
$\Delta R_{1 t}$ & $-11.45^{* * *}$ & 0.098 & $-24.62^{* * *}$ & $65.53^{* * *}$ \\
$\Delta R_{2 t}$ & $-5.45^{* * *}$ & 0.096 & $-24.97^{* * *}$ & $98.91^{* * *}$ \\
$\Delta R_{3 t}$ & $-8.77^{* * *}$ & 0.095 & $-24.68^{* * *}$ & $98.57^{* * *}$ \\
$\Delta R_{4 t}$ & $-4.97^{* * *}$ & 0.105 & $-25.26^{* * *}$ & $84.60^{* * *}$ \\
Critical values & & & & \\
$1 \%$ (Constant and trend) & -3.97 & 0.216 & -3.97 & 8.80 \\
$5 \%$ (Constant and trend) & -3.42 & 0.146 & -3.42 & 6.61 \\
$1 \%$ (Constant only) & -3.44 & 0.739 & -3.44 & 6.95 \\
$5 \%$ (Constant only) & -2.86 & 0.463 & -2.87 & 4.95 \\
\hline
\end{tabular}

Notes: ${ }^{* * *}$ indicates that the null hypothesis is rejected at the 1 percent level of significance. 
Table 3.

Estimated long-run relationship between the standard variable mortgage rate and the cash rate. $\hat{R}_{i t}=\hat{\theta}_{0 i}+\hat{\theta}_{1 i} T_{t}+\hat{\theta}_{2 i} C_{t}$

\begin{tabular}{|c|c|c|c|c|c|c|c|c|}
\hline \multirow[b]{2}{*}{ Coefficients } & \multicolumn{2}{|c|}{ ANZ } & \multicolumn{2}{|c|}{ CBA } & \multicolumn{2}{|c|}{ NAB } & \multicolumn{2}{|c|}{ WBC } \\
\hline & $\begin{array}{c}\text { Constant } \\
\text { only }\end{array}$ & $\begin{array}{c}\text { Constant and } \\
\text { trend }\end{array}$ & $\begin{array}{c}\text { Constant } \\
\text { only }\end{array}$ & $\begin{array}{c}\text { Constant and } \\
\text { trend }\end{array}$ & $\begin{array}{c}\text { Constant } \\
\text { only }\end{array}$ & Constant and trend & $\begin{array}{c}\text { Constant } \\
\text { only }\end{array}$ & $\begin{array}{c}\text { Constant and } \\
\text { trend } \\
\end{array}$ \\
\hline$\hat{\theta}_{0 i}$ & $3.427^{* * *}$ & $2.717^{* * *}$ & $3.286^{* * *}$ & $2.611^{* * *}$ & $3.248^{* * *}$ & $2.596^{* * *}$ & $3.528^{* * *}$ & $2.917^{* * *}$ \\
\hline$\hat{\theta}_{1 i}$ & - & $0.003^{* * *}$ & - & $0.002^{* * *}$ & - & $0.002^{* * *}$ & - & $0.002^{* * *}$ \\
\hline$\hat{\theta}_{2 i}$ & $0.754^{* * *}$ & $0.748^{* * *}$ & $0.778^{* * *}$ & $0.769^{* * *}$ & $0.780^{* * *}$ & $0.777^{* * *}$ & $0.743^{* * *}$ & $0.727^{* * *}$ \\
\hline$R^{2}$ & 0.733 & 0.973 & 0.742 & 0.97 & 0.785 & 0.977 & 0.729 & 0.963 \\
\hline $\bar{R}^{2}$ & 0.731 & 0.972 & 0.741 & 0.969 & 0.782 & 0.976 & 0.728 & 0.961 \\
\hline No. of leads & 4 & 16 & 1 & 16 & 6 & 18 & 0 & 18 \\
\hline No. of lags & 0 & 14 & 0 & 12 & 0 & 12 & 0 & 10 \\
\hline$H_{0}: \theta_{2 i}=1$ & $F(1,574)=26.8^{* * *}$ & $F(1,535)=223.5^{* * *}$ & $F(1,577)=22.8^{* * *}$ & $F(1,539)=162.0^{* * *}$ & $F(1,572)=26.1^{* * *}$ & $F(1,537)=208.8^{* * *}$ & $F(1,578)=31.7^{* * *}$ & $F(1,541)=198.0^{* * *}$ \\
\hline \multicolumn{9}{|c|}{ Unit root test results for the residuals $\hat{\varepsilon}_{i t}$} \\
\hline $\mathrm{ADF}$ & -0.941 & $-5.460^{* * *}$ & -0.714 & $-4.734^{* * *}$ & -1.472 & $-6.126^{* * *}$ & -0.588 & $-4.196^{* * *}$ \\
\hline KPSS & $2.811^{* * *}$ & 0.287 & $2.703^{* * *}$ & 0.338 & $2.816^{* * *}$ & 0.25 & $2.601^{* * *}$ & 0.32 \\
\hline PP & -1.962 & $-6.025^{* * *}$ & -1.337 & $-4.594^{* * *}$ & -1.643 & $-6.029^{* * *}$ & -0.994 & $-4.457^{* * *}$ \\
\hline EG & 1.89 & $20.85^{* * *}$ & 4.99 & $11.60^{* * *}$ & 2.11 & $20.02^{* * *}$ & 2.49 & $10.89^{* * *}$ \\
\hline \multicolumn{9}{|c|}{ Critical values (constant only): } \\
\hline Level & $\mathrm{ADF}$ & KPSS & $\mathrm{PP}$ & EG & & & & \\
\hline $1 \%$ & -3.442 & 0.739 & -3.442 & 6.95 & & & & \\
\hline $5 \%$ & -2.867 & 0.463 & -2.867 & 4.95 & & & & \\
\hline
\end{tabular}

Notes: $^{* *}$ and ${ }^{* * *}$ indicate that the null hypothesis is rejected at the 5 and 1 percent level of significance, respectively. 
Table 4.

Estimated asymmetric short-run dynamic models.

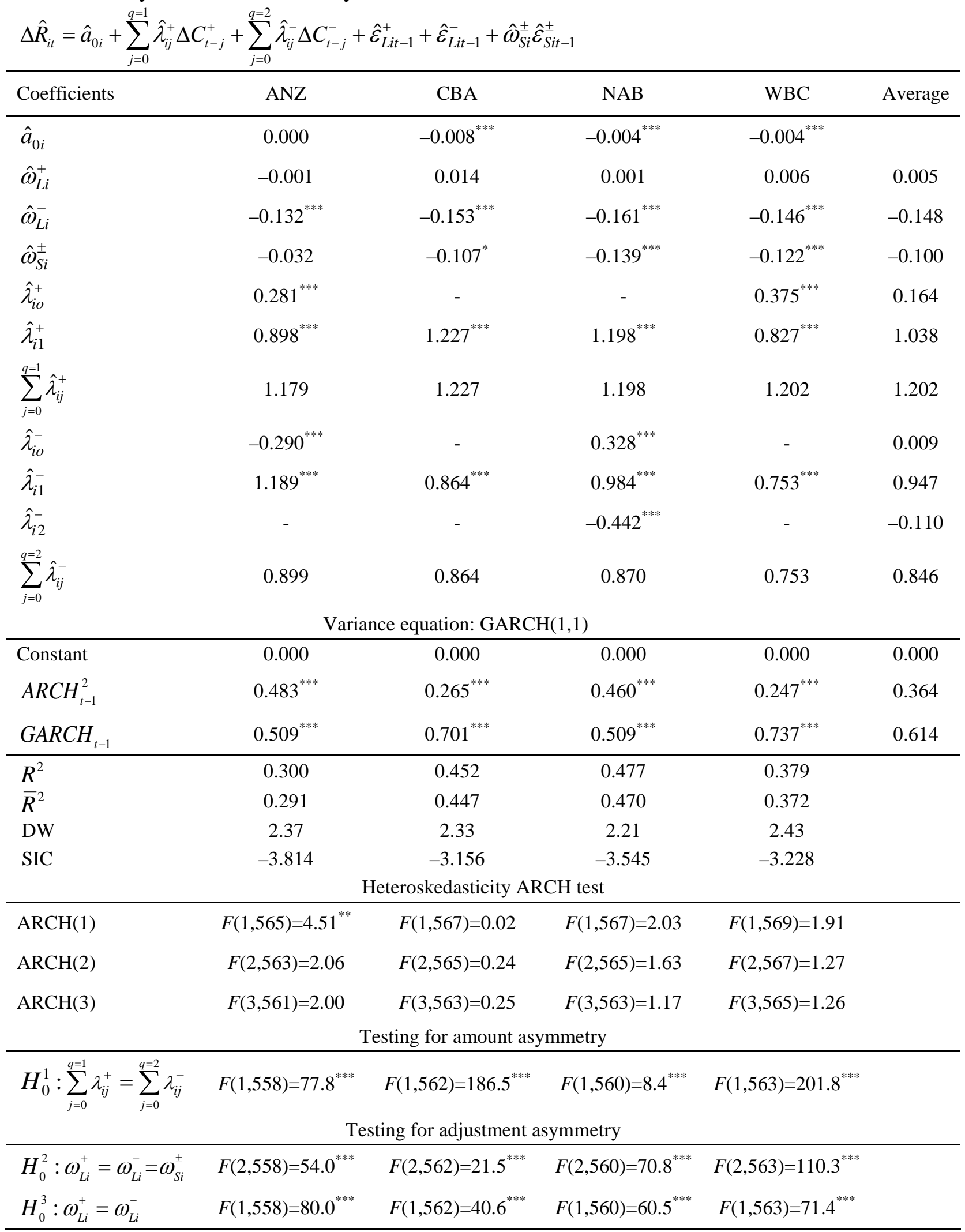

Note: ${ }^{*}{ }^{* *}$ and ${ }^{* * *}$ indicate that the corresponding null hypotheses are rejected at the 10,5 and $1 \%$ levels of significance, respectively. 
Table 5

The number of non-zero observations given various values taken by $\hat{\varepsilon}_{i t}$ and $\Delta C_{i}$.

\begin{tabular}{lcccccc}
\hline Variable & ANZ & CBA & NAB & WBC & Average & Average \% \\
\hline$\hat{\varepsilon}_{t} \geq 0.44 \hat{\sigma}$ & 162 & 184 & 158 & 197 & 175 & 31 \\
$\hat{\varepsilon}_{t} \leq-0.44 \hat{\sigma}$ & 197 & 196 & 171 & 187 & 188 & 33 \\
$-0.44 \hat{\sigma}<\hat{\varepsilon}_{t}<0.44 \hat{\sigma}$ & 209 & 190 & 241 & 188 & 207 & 36 \\
Total & 568 & 570 & 570 & 572 & 570 & 100 \\
& & & & & & \\
\hline$\Delta C_{t}>0$ & 38 & & & & & \\
$\Delta C_{t}>0$ & 28 & & & & & \\
$\Delta C_{t}=0$ & 515 & & & & & \\
Total & 581 & & & & & \\
\hline
\end{tabular}


Table 6

Average response time of the Big-4 banks to changes in the cash rate.

\begin{tabular}{|c|c|c|c|c|c|c|}
\hline \multirow{2}{*}{ Date } & \multirow{2}{*}{$\begin{array}{c}\text { Rate change } \\
\text { (\%) }\end{array}$} & ANZ & CBA & NAB & WBC & \multirow{2}{*}{ Average } \\
\hline & & \multicolumn{4}{|c|}{ First response to rate cuts (in weeks) } & \\
\hline $12 / 02 / 2001$ & -0.50 & 1 & 1 & 1 & 1 & 1.0 \\
\hline $12 / 03 / 2001$ & -0.25 & 1 & 1 & 1 & 1 & 1.0 \\
\hline 09/04/2001 & -0.50 & 1 & 1 & 1 & 1 & 1.0 \\
\hline 10/09/2001 & -0.25 & 1 & 1 & 1 & 1 & 1.0 \\
\hline 08/10/2001 & -0.25 & 1 & 1 & 1 & 1 & 1.0 \\
\hline $10 / 12 / 2001$ & -0.25 & 1 & 1 & 1 & 1 & 1.0 \\
\hline 08/09/2008 & -0.25 & 11 & 1 & 10 & 1 & 5.8 \\
\hline $13 / 10 / 2008$ & -1.00 & 6 & 5 & 5 & 3 & 4.8 \\
\hline $10 / 11 / 2008$ & -0.75 & 2 & 1 & 1 & 1 & 1.3 \\
\hline 08/12/2008 & -1.00 & 1 & 1 & 1 & 1 & 1.0 \\
\hline 09/02/2009 & -1.00 & 1 & 1 & 1 & 1 & 1.0 \\
\hline 13/04/2009 & -0.25 & 1 & 1 & - & - & 1.0 \\
\hline 07/11/2011 & -0.25 & 2 & 1 & 1 & 2 & 1.5 \\
\hline \multirow[t]{2}{*}{$12 / 12 / 2011$} & -0.25 & 2 & 2 & 2 & 2 & 2.0 \\
\hline & \multicolumn{6}{|c|}{ First response to rate rises (in weeks) } \\
\hline $13 / 05 / 2002$ & 0.25 & 15 & 17 & 17 & 19 & 17.0 \\
\hline 10/06/2002 & 0.25 & 11 & 13 & 13 & 15 & 13.0 \\
\hline $10 / 11 / 2003$ & 0.25 & 1 & 1 & 1 & 1 & 1.0 \\
\hline 08/12/2003 & 0.25 & 1 & 1 & 1 & 1 & 1.0 \\
\hline 07/03/2005 & 0.25 & 1 & 1 & 1 & 2 & 1.3 \\
\hline 08/05/2006 & 0.25 & 1 & 1 & 1 & 1 & 1.0 \\
\hline 07/08/2006 & 0.25 & 1 & 1 & 1 & 1 & 1.0 \\
\hline $13 / 11 / 2006$ & 0.25 & 1 & 1 & 1 & 1 & 1.0 \\
\hline 13/08/2007 & 0.25 & 1 & 1 & 1 & 1 & 1.0 \\
\hline $12 / 11 / 2007$ & 0.25 & 2 & 1 & 1 & 1 & 1.3 \\
\hline $11 / 02 / 2008$ & 0.25 & 1 & 1 & 1 & 1 & 1.0 \\
\hline $10 / 03 / 2008$ & 0.25 & 2 & 1 & 4 & 2 & 2.3 \\
\hline $12 / 10 / 2009$ & 0.25 & 1 & 1 & 1 & 1 & 1.0 \\
\hline 09/11/2009 & 0.25 & 1 & 1 & 1 & 1 & 1.0 \\
\hline 07/12/2009 & 0.25 & 1 & 1 & 1 & 1 & 1.0 \\
\hline 08/03/2010 & 0.25 & 1 & 1 & 1 & 1 & 1.0 \\
\hline $12 / 04 / 2010$ & 0.25 & 1 & 1 & 1 & 1 & 1.0 \\
\hline $10 / 05 / 2010$ & 0.25 & 1 & 1 & 1 & 1 & 1.0 \\
\hline 08/11/2010 & 0.25 & 2 & 1 & 2 & 1 & 1.5 \\
\hline
\end{tabular}

Sources: RBA (2012b), data purchased from canstar.com.au, and the authors' calculations. 


\section{Table 7}

Granger causality test results based on a four-variable VAR model.

$$
\Delta \hat{R}_{i t}=\hat{\xi}_{i 0}+\sum_{j=1}^{k=4} \hat{\phi}_{i j} \Delta \hat{R}_{1 t-j}+\sum_{j=1}^{k=4} \hat{\varphi}_{i j} \Delta \hat{R}_{2 t-j}+\sum_{j=1}^{k=4} \hat{\mu}_{i j} \Delta \hat{R}_{3 t-j}+\sum_{j=1}^{k=4} \hat{\eta}_{i j} \Delta \hat{R}_{4 t-j}
$$

$\begin{array}{cc}\text { Null hypothesis } H_{0} & \text { Alternative } \\ \text { hypothesis } H_{1}\end{array}$

F-stat.

CBA $\left(\Delta R_{2}\right)$ does not Granger cause $\operatorname{ANZ}\left(\Delta R_{1}\right) \quad \varphi_{11}=\varphi_{12}=\varphi_{13}=\varphi_{14}=0 \quad$ At least one $\varphi_{1 j} \neq 0 \quad F(4,559)=7.97^{* * *}$ $\operatorname{NAB}\left(\Delta R_{3}\right)$ does not Granger cause ANZ $\left(\Delta R_{1}\right) \quad \mu_{11}=\mu_{12}=\mu_{13}=\mu_{14}=0$ At least one $\mu_{1 j} \neq 0 \quad F(4,559)=7.07^{* * *}$ $\operatorname{WBC}\left(\Delta R_{4}\right)$ does not Granger cause $\operatorname{ANZ}\left(\Delta R_{1}\right) \quad \eta_{11}=\eta_{12}=\eta_{13}=\eta_{14}=0 \quad$ At least one $\eta_{1 j} \neq 0 \quad F(4,559)=7.87^{* * *}$ $\operatorname{ANZ}\left(\Delta R_{1}\right)$ does not Ganger cause $\operatorname{CBA}\left(\Delta R_{2}\right) \quad \phi_{21}=\phi_{22}=\phi_{23}=\phi_{24}=0 \quad$ At least one $\phi_{2 j} \neq 0 \quad F(4,559)=10.39$ $\operatorname{NAB}\left(\Delta R_{3}\right)$ does not Granger cause $\operatorname{CBA}\left(\Delta R_{2}\right) \quad \mu_{21}=\mu_{22}=\mu_{23}=\mu_{24}=0$ At least one $\mu_{2 j} \neq 0 \quad F(4,559)=2.65^{* *}$ $\operatorname{WBC}\left(\Delta R_{4}\right)$ does not Granger cause $\operatorname{CBA}\left(\Delta R_{2}\right) \quad \eta_{21}=\eta_{22}=\eta_{23}=\eta_{24}=0 \quad$ At least one $\eta_{2 j} \neq 0 \quad F(4,559)=31.63^{* * *}$ $\operatorname{ANZ}\left(\Delta R_{1}\right)$ does not Granger cause NAB $\left(\Delta R_{3}\right) \quad \phi_{31}=\phi_{32}=\phi_{33}=\phi_{34}=0 \quad$ At least one $\phi_{3 j} \neq 0 \quad F(4,559)=11.34^{* * *}$ CBA $\left(\Delta R_{2}\right)$ does not Granger cause $\operatorname{NAB}\left(\Delta R_{3}\right) \quad \varphi_{31}=\varphi_{32}=\varphi_{33}=\varphi_{34}=0 \quad$ At least one $\varphi_{3 j} \neq 0 \quad F(4,559)=4.26^{* * *}$ $\operatorname{WBC}\left(\Delta R_{4}\right)$ does not Granger cause $\operatorname{NAB}\left(\Delta R_{3}\right) \quad \eta_{31}=\mu_{32}=\mu_{33}=\mu_{34}=0 \quad$ At least one $\mu_{3 j} \neq 0 \quad F(4,559)=43.83^{* * *}$ $\operatorname{ANZ}\left(\Delta R_{1}\right)$ does not Granger cause $\operatorname{WBC}\left(\Delta R_{4}\right) \quad \phi_{41}=\phi_{42}=\phi_{43}=\phi_{44}=0 \quad$ At least one $\phi_{4 j} \neq 0 \quad F(4,559)=3.26^{* * *}$ CBA $\left(\Delta R_{2}\right)$ does not Granger cause $\operatorname{WBC}\left(\Delta R_{4}\right) \quad \varphi_{41}=\varphi_{42}=\varphi_{43}=\varphi_{44}=0 \quad$ At least one $\varphi_{4 j} \neq 0 \quad F(4,559)=2.75^{* *}$ $\operatorname{NAB}\left(\Delta R_{3}\right)$ does not Granger cause $\operatorname{WBC}\left(\Delta R_{4}\right) \quad \mu_{41}=\mu_{42}=\mu_{43}=\mu_{44}=0 \quad$ At least one $\mu_{4 j} \neq 0 \quad F(4,559)=1.13$ Notes: ${ }^{*},{ }^{* *}$ and ${ }^{* * *}$ indicate that the null hypothesis is rejected at the 10,5 and 1 percent level of significance, respectively. 